\title{
Development of P/M Fe-P soft magnetic materials
}

\author{
S K CHAURASIA, UJJWAL PRAKASH*, P S MISRA and K CHANDRA \\ Department of Metallurgical and Materials Engineering, IIT Roorkee, Uttarakhand 247 667, India
}

MS received 21 October 2009; revised 16 August 2011

\begin{abstract}
Phosphorous is treated as an impurity in conventional steels owing to segregation of phosphorous and formation of brittle phosphides along the grain boundaries. It is responsible for cold and hot shortness in wrought steels. In conventional powder metallurgy, involving compaction and sintering, high phosphorous content (up to $\mathbf{0 . 7 \%}$ ) in Fe-based alloys exhibit attractive set of mechanical and magnetic properties. These powder-processed alloys suffer from increasing volumetric shrinkage during sintering as phosphorous is increased beyond 0.6\%. Thus both cast as well as conventional powder metallurgy routes have their own limitations in dealing with iron-phosphorous alloys. Hot-powder forging was used in the present investigation for the development of high-density soft magnetic materials containing $\mathbf{0} \cdot \mathbf{3}-\mathbf{0} \cdot \mathbf{8} \%$ phosphorous to overcome these difficulties. It was observed that phosphorous addition improves the final density of the resulting product. It was further observed that hot-forged iron-phosphorous alloys have excellent hot/cold workability and could be easily shaped to thin strips (0.5-1.0 mm thick) and wires (0.5-1.0 mm diameter). The powder hot-forged alloys were characterized in terms of microstructure, porosity content/densification, hardness, soft magnetic properties and electrical resistivity. Magnetic properties such as coercivity 0.35-1.24 Oe, saturation magnetization 14145-17490 G and retentivity 6402-10836 G were observed. The obtained results were discussed based on the microstructures evolved.
\end{abstract}

Keywords. Fe-P alloys; soft magnetic materials; Hot-powder forging; thermomechanical processing; resistivity; magnetic properties.

\section{Introduction}

In conventional steels, phosphorous levels are kept below $0.05 \%$ because it is responsible for cold and hot shortness in wrought steels. This is due to phosphorous segregation at the grain boundaries (Hopkins and Tipler 1958). Powder metallurgy $(\mathrm{P} / \mathrm{M})$ processing allows alloying of an element to a higher amount if so desired, which is not possible through melting route. Manufacture of advanced soft magnetic materials involving new compositions (such as $\mathrm{P}, \mathrm{Si}$ etc.) and complicated parts are feasible through powder metallurgy processing. Density is the most important parameter in this context (Rutz and Hanejko 1994).

Near full density pure iron powder metallurgy parts can be easily manufactured using conventional powder metallurgical process. However, pure iron powder metallurgy parts have very low resistivity and therefore, suffer from high magnetic losses due to high amount of eddy current generation. To increase its resistivity without sacrificing the flux density, phosphorous is alloyed with iron. Phosphorous is normally admixed with atomized iron powder. When compacted, compressibility of soft iron is realized without the loss of green density because the hard and fine $10 \mu \mathrm{m} \mathrm{Fe}{ }_{2} \mathrm{P}$ or $\mathrm{Fe}_{3} \mathrm{P}$ particles rearrange themselves among the large iron particles as compaction occurs. When sintered, the ironphosphorous intermetallic compounds melt at a temperature

\footnotetext{
*Author for correspondence (ujwalfmt@iitr.ernet.in)
}

of $1323 \mathrm{~K}$ and diffuse into the iron, forming a solid solution of phosphorous in iron. The liquid phase enhances diffusion rates and assists in the rearrangement of the pores and particle boundaries, thereby further densifying the iron. Because magnetic induction is a linear function of the sintered density, the magnetic induction realized from the phosphorous iron alloys is higher than that realized from the pure iron parts (Moyer 1998).

Phosphorous is also known to increase electrical resistivity, permeability and decrease coercivity, thus improving the soft magnetic performance of pure iron. It also significantly improves ductility and toughness of P/M Fe-P based alloys (Lindskog et al 1977; Lund 1985). However, the drawback to the use of phosphorous iron parts is that, owing to the liquid phase sintering that occurs, dimensional control is more difficult. If we follow the traditional powder metallurgical process, such as compaction and sintering, for manufacturing of $\mathrm{Fe}-\mathrm{P}$ alloys, heavy volume shrinkage will be experienced. (Lindskog et al 1977; Moyer 1998). Consequently, phosphorous higher than $0.6 \mathrm{wt} \%$ is not normally recommended in conventional powder metallurgy process involving compacting and sintering, although higher phosphorous up to $2 \%$ is reported to continue to improve magnetic properties of these alloys (Moyer 1998). There are several other densification processes available in the literature. Out of all, hot isostatic processing is the best so far as density and performance of these powder metallurgy parts are concerned. However, the process is extremely costly (Das et al 2008). 
Table 1. Specification of atomized powder.

Atomized iron powder grade no.
Manufactured by
Particle size
Apparent density
Flow
Compressibility
Hydrogen loss percentage
Carbon content

Atomized iron powder grade no.

Manufactured by

Apparent density

Flow

Hydrogen loss percentage

Carbon content

\author{
AHC100.29 \\ M/S HOGANAS AB, Sweden \\ $0.17 \mathrm{~mm}$ \\ $2.59 \mathrm{gm} / \mathrm{cc}$ \\ $25-28$ second per $50 \mathrm{gm}$ \\ $6.65-6.68 \mathrm{gm} / \mathrm{cc}$ \\ $0 \cdot 1-0 \cdot 2$ (i.e. reducible oxygen content) \\ $0 \cdot 01-0 \cdot 02$
}

In the present investigation, the above problems were nullified by using hot-powder forging technique (Sudan and Misra 1991; Chandra 2004). This process provides highest possible densification of these alloys and a vivid description of this process was provided by Das et al (2008). All these alloys were reduced to very thin gauge of sheet and wire by hot working. These alloys show very low coercivity values $0.35-1.24$ Oe and very high saturation magnetization and resistivity values.

\section{Experimental}

Fe-10\% P master alloy powder was prepared by mixing water and atomized iron powder with ortho-phosphoric acid. The specifications of the atomized powder used are given in table 1 . The powder blends were made by mixing the atomized iron powder and the master alloy (iron-phosphate) in appropriate proportion for making $\mathrm{Fe}-0 \cdot 30 \mathrm{P}, \mathrm{Fe}-0 \cdot 35 \mathrm{P}$, $\mathrm{Fe}-0.45 \mathrm{P}, \mathrm{Fe}-0.65 \mathrm{P}$ and $\mathrm{Fe}-0.80 \mathrm{P}$ alloys. Mixing was done mechanically in a laboratory jar mill for $2-3 \mathrm{~h}$. The mechanically mixed powder was encapsulated in mild steel cylindrical can (capsule) of $50 \mathrm{~mm}$ OD, $40 \mathrm{~mm}$ ID and $100 \mathrm{~mm}$ length. The encapsulated powders were thus heated in a tubular furnace at $1050^{\circ} \mathrm{C}$ for $30 \mathrm{~min}$ in dry hydrogen atmosphere. Process details have already been given elsewhere (Das et al 2008).

During heating, the powder encapsules were rotated for complete reduction of powder. The $\mathrm{H}_{2}$ atmosphere would remove oxide layer from the surfaces of the powders heated at high temperatures. The product at the iron particle surface i.e. $\mathrm{Fe}_{3}\left(\mathrm{PO}_{4}\right)_{2}$ would be reduced to iron-phosphide $\left(\mathrm{Fe}_{3} \mathrm{P}\right)$, during heating. The capsule was taken out and hot forged in a $100 \mathrm{mt}$ friction screw driven forge press. After the first blow of the hammer the supply of $\mathrm{H}_{2}$ gas was closed. Heated capsules were then forged in the press to make slabs using a channel die. Only three strokes were required to form a slab of thickness $15 \mathrm{~mm}$ including the mild steel skin.

The forged slabs were then homogenized at $1100^{\circ} \mathrm{C}$ for $1 \mathrm{~h}$ in a muffle furnace followed by air cooling to ensure uniform distribution of alloying elements. The additional purpose of homogenization is to eliminate brittle non-equilibrium phases along grain/particle boundaries. After homogenization, the ends of mild steel capsule were cut off and the mild steel encapsulation was also removed by machining. A forged slab about $7 \mathrm{~mm}$ thickness was thus obtained and representative samples were prepared from the forged slabs for density measurement, hardness test and microstructural studies. The forged slabs, after removal of mild steel skin, were hot rolled using flat roll and section rolls at $\sim 1000^{\circ} \mathrm{C}$ to make thin sheets $(0 \cdot 5-1 \mathrm{~mm}$ thickness) and wire $(3 \mathrm{~mm}$ diameter), respectively. For making thin sheets and wire of said thickness, 25-30 roll passes were required. The final two passes were given at the room temperature during rolling of each sheet and wire. All the compositions developed in the present investigation had excellent hot/cold rolling response and no failure by way of cracking was observed. Rolled wires were passed through wire drawing dies to draw the wires of $0 \cdot 5-1 \mathrm{~mm}$ diameter. The process flow chart is given in figure 1 .

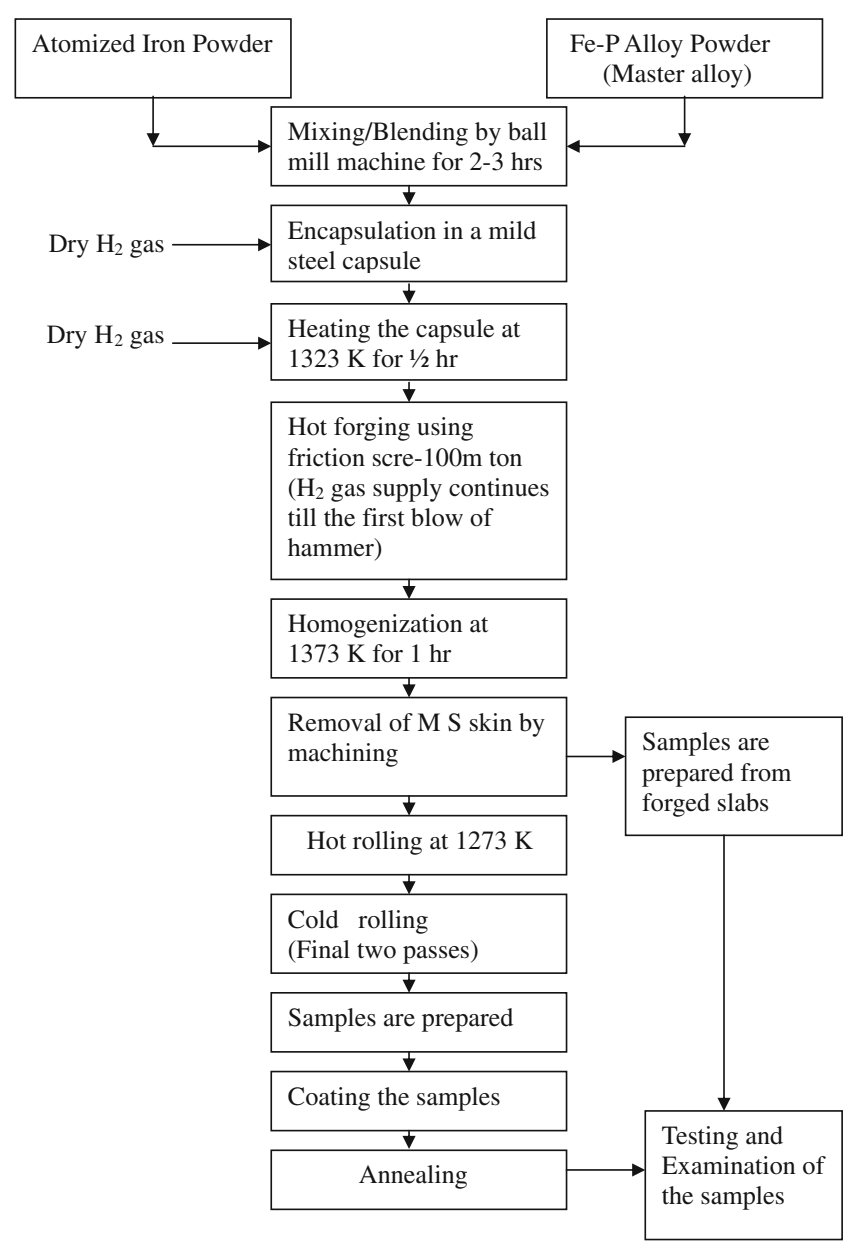

Figure 1. Process flow chart. 
Table 2. Volume percentage of porosities of alloys.

\begin{tabular}{lcccc}
\hline Materials & $\begin{array}{c}\text { Forged } \\
\text { density }(\mathrm{g} / \mathrm{cc})\end{array}$ & $\begin{array}{c}\text { Rolled and annealed } \\
\text { density }(\mathrm{g} / \mathrm{cc})\end{array}$ & $\begin{array}{c}\text { Volume \% porosity } \\
\text { in forged slabs }\end{array}$ & $\begin{array}{c}\text { Volume \% porosity in } \\
\text { rolled and annealed }\end{array}$ \\
\hline $\mathrm{Fe}-0.30 \mathrm{P}$ & 7.60 & 7.74 & 5.66 & 3.16 \\
$\mathrm{Fe}-0.35 \mathrm{P}$ & 7.64 & 7.76 & 5.35 & 3.00 \\
$\mathrm{Fe}-0.45 \mathrm{P}$ & 7.67 & 7.79 & 4.83 & 2.50 \\
$\mathrm{Fe}-0.65 \mathrm{P}$ & 7.69 & 7.80 & 4.50 & 2.25 \\
$\mathrm{Fe}-0.80 \mathrm{P}$ & 7.71 & 7.82 & 3.50 & 1.65 \\
\hline
\end{tabular}

Rings (toroids) were stamped from the sheets using a die/punch arrangement. The rolled sheets, stamped toroids and wires were annealed by keeping them in muffle furnace at $920^{\circ} \mathrm{C}$ for $20 \mathrm{~min}$ and then cooling in the furnace. For annealing, the rolled sheets, toroids and wires were first coated with a ceramic coating (developed in Metallurgical and Materials Engineering Department, IIT Roorkee as proprietary item) to prevent the oxidation. The burnt coating from the surface of the samples was removed and cleaned by gently rubbing with a coarse and a fine grain emery papers, respectively.

Density of the forged and homogenized as well as rolled and annealed samples was measured using the Archimedes principle and it was in the range of 7.74-7.82 gm/cc. The magnetic characteristics of the samples made in the shape of a toroid ring were determined using hysteresis loop tracers (HLT-SOFT). In the present investigation the toroids were wound with 71 primary and 10 secondary turns. The magnetic properties of corresponding wire samples were measured using hystersis loop tracer model no. HLT111. The working of the unit was described elsewhere (Das 2006).

The resistivity of the sheet samples was determined by the four probe method. The dimensions of the surface plates used for resistivity measurement were $1 \mathrm{~mm}$ thickness (max.) $\times$ $5 \mathrm{~mm}$ breadth $(\mathrm{min}) \times 12 \mathrm{~mm}$ length $(\mathrm{min})$.

The hot-rolled and annealed sample sections were mounted in bakelite using hot mounting press and mechanically polished to $1 \mu \mathrm{m}$ surface finish and etched in $4 \%$ Nital for metallographic and scanning electron microscopy (SEM) examinations. The volume percentage porosity was measured by the optical microscope. Brinell hardness measurements were taken for the mounted specimens and also for the forged specimens.

\section{Results and discussion}

Five powder metallurgical alloys $\mathrm{Fe}-0 \cdot 30 \mathrm{P}, \mathrm{Fe}-0 \cdot 35 \mathrm{P}, \mathrm{Fe}-$ $0.45 \mathrm{P}, \mathrm{Fe}-0.65 \mathrm{P}$ and $\mathrm{Fe}-0.80 \mathrm{P}$ were made in the present investigation and the measured density values are shown in table 2. It may be seen that the density of binary Fe-P alloys increases with increase in $\mathrm{P}$ content. Though the increase in density on phosphorous addition was reported earlier, these values are better than the values $(7 \cdot 16-7.46 \mathrm{~g} / \mathrm{cc}$ ) reported for $\mathrm{P} / \mathrm{M}$ alloys with phosphorous content 0.30 to
$1 \mathrm{wt} \% \mathrm{P}$ prepared by conventional pressing and sintering route (Lindskog et al 1977). Further, the density of as-forged $\mathrm{Fe}-0.45 \mathrm{P}(7.79 \mathrm{gm} / \mathrm{cc})$ and $\mathrm{Fe}-0.80 \mathrm{P}(7.82 \mathrm{gm} / \mathrm{cc})$ alloys

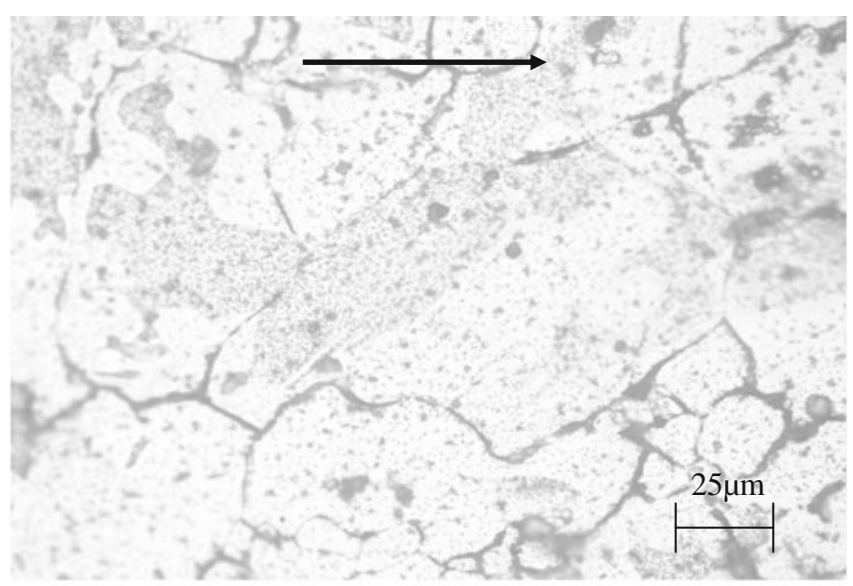

(a) Fe-0.30P Alloy

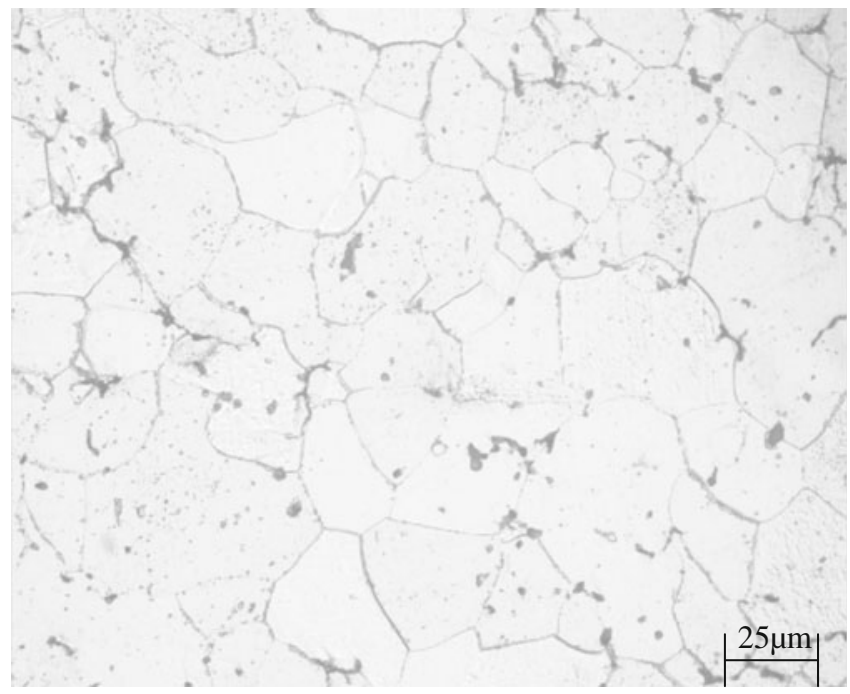

(b) Fe-0.65P Alloy

Figure 2. (a) Microstructure of rolled and annealed alloys along rolling direction $(\rightarrow)$ and (b) Microstructure of rolled and annealed alloys. Figures show the single phase with porosity distributed along grain boundaries as well as inside the grains for entire range of phosphorous in these alloys. Some of them are of irregular size and shape and some are elongated along rolling direction as shown in figure 2a. 


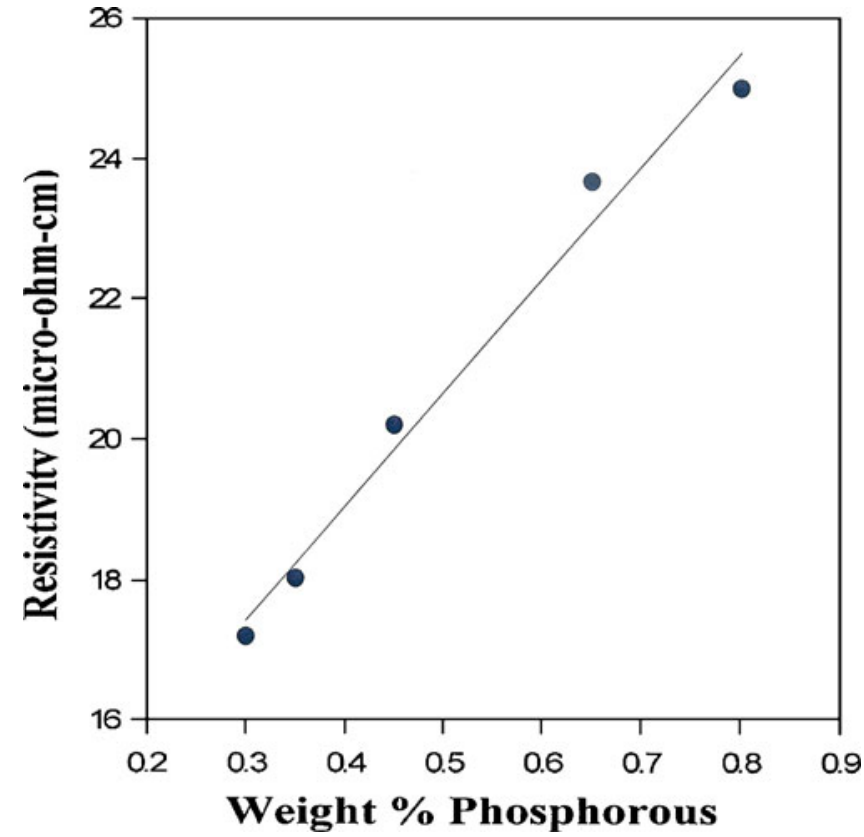

Figure 3. Variation of resistivity with phosphorous content in annealed $\mathrm{Fe}-\mathrm{P}$ alloy sheets.

produced in the present investigation by hot forging of encapsulated powder and rolling is higher than the density values reported for conventionally processed $\mathrm{Fe}-0.45 \mathrm{P}$ $(7.45 \mathrm{gm} / \mathrm{cc})$ and $\mathrm{Fe}-0.80 \mathrm{P}(7.41 \mathrm{gm} / \mathrm{cc})$ alloys that were compacted at $689.5 \mathrm{MPa}(50 \mathrm{tsi})$ and sintered at $1260^{\circ} \mathrm{C}$ (Hanejko et al 1992). Thus, powder-forging route used in the present work has yielded better densification than the conventional pressing and sintering route.

Increase in density by phosphorous addition has been reported earlier as well (Hanejko et al 1992) when compacting and sintering route of shaping was adopted. However, in that case increase in density was due to high compacting pressure followed by high temperature liquid phase sintering. In the present case no separate sintering is involved and yet there is significant improvement in density (more than that of compacting and sintering route as stated above) that too at relatively low temperature processing where no liquid phase is involved.

All the alloys exhibited single-phase recrystallized grain structure with porosity within or at the grain boundary regions. This is in agreement with the ferrite structure observed at these compositions (Das et al 2008). Porosity decreases with increase in phosphorous content. The longitudinal cross sections showed porosity elongated along the rolling direction while the transverse cross sections showed the almost rounded porosity. The rolled and annealed sections of wire were etched to reveal grain boundaries and one of the microstructure is shown in figure 2. It is noteworthy that the grain structure consists of equi-axed grains (figure 2a) and there is no effect of rolling direction on grain deformation/orientation.
Electrical resistivity increases linearly with increase in phosphorous content (figure 3 ) which supports the findings of earlier work reported by Lindskog et al (1977) and Panasyuk et al (1973). It was reported (Panasyuk et al 1973) that phosphorous additions increase the electrical resistivity of iron to $19 \mu \Omega$-cm at $0.50 \% \mathrm{P}$ and $22 \mu \Omega$-cm at $1 \% \mathrm{P}$. It was also been reported (Shimada et al 2003) that the resistivity increases linearly from $13.0 \mu \Omega$-cm to $29 \mu \Omega$-cm for pure iron with $1 \%$ phosphorous.

Alloy hardness increases with increasing phosphorous content (figures 4 and 5). Phosphorous causes more hardening of ferrite than silicon in solid solution with iron (Das

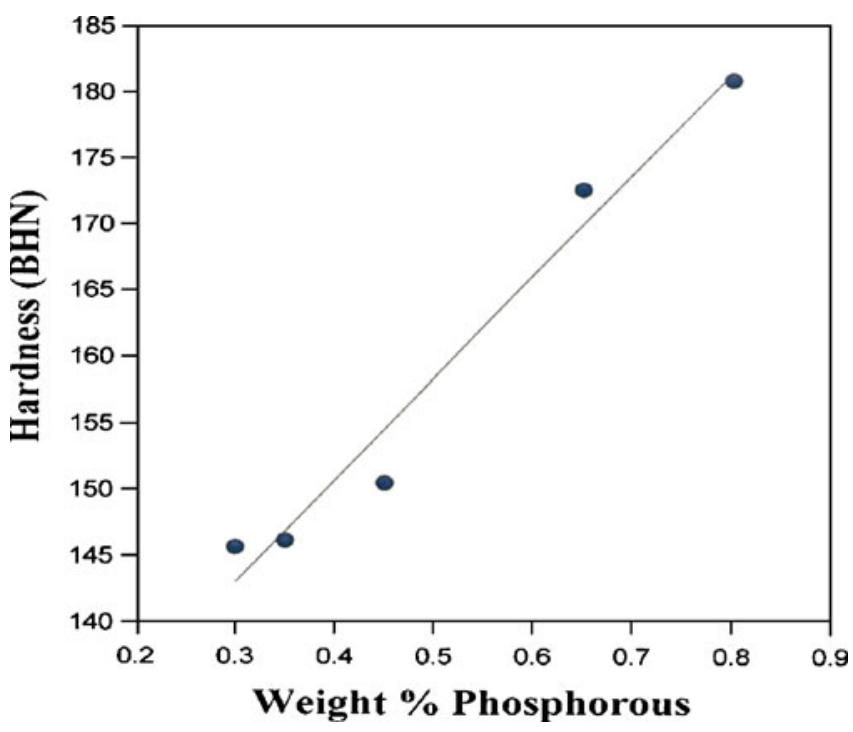

Figure 4. Variation of hardness with phosphorous for Fe-P alloys as forged and homogenized sheets.

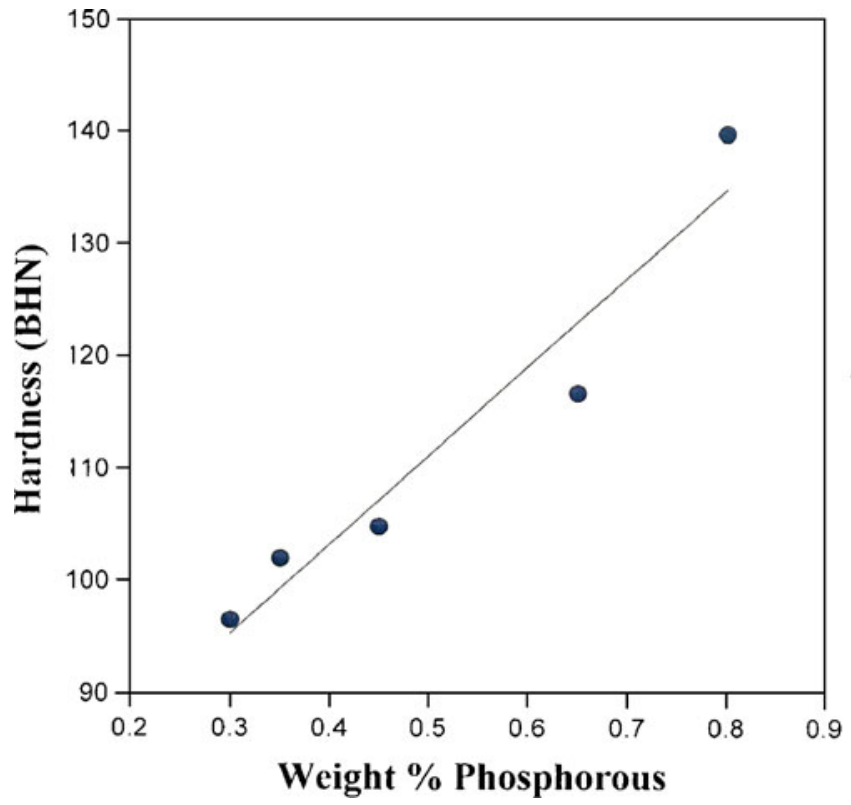

Figure 5. Variation of hardness with phosphorous for Fe-P alloys as rolled and annealed wires. 


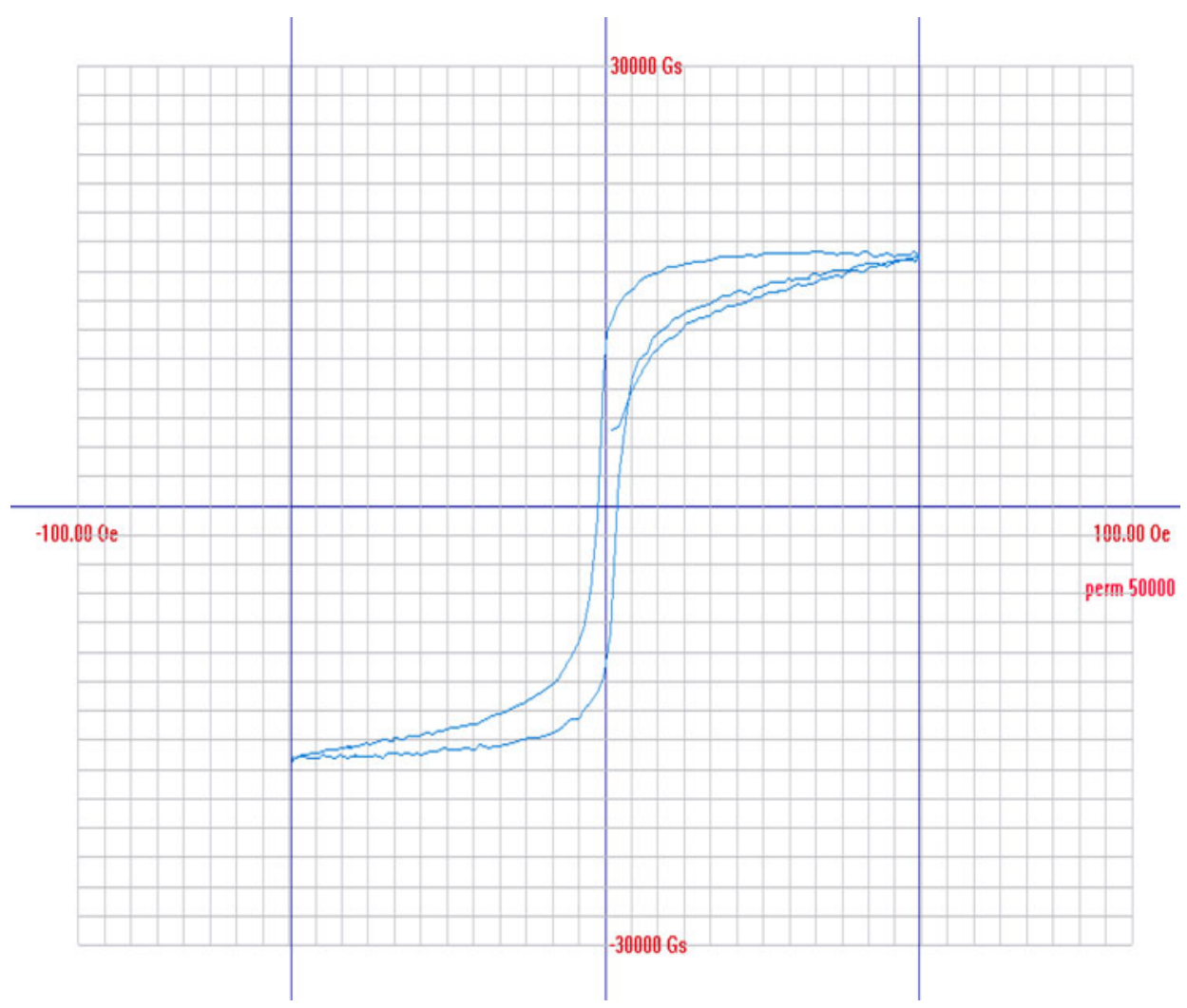

Figure 6. Hysteresis (B-H) curves for $\mathrm{Fe}-0 \cdot 45 \mathrm{P}$ toroid sample under d.c. mode.

Table 3. Coercivity, saturation, magnetization, retentivity and permeability values of alloys under d.c. mode.

\begin{tabular}{lcccc}
\hline Alloy & $\begin{array}{c}\text { Coercivity } \\
(\mathrm{Oe})\end{array}$ & $\begin{array}{c}\text { Sat. magnetization } \\
(G)\end{array}$ & $\begin{array}{c}\text { Retentivity } \\
(G)\end{array}$ & $\begin{array}{c}\text { Permeability } \\
(\mu)\end{array}$ \\
\hline $\mathrm{Fe}-0 \cdot 30 \mathrm{P}$ & $1 \cdot 241$ & 14415 & 8121 & 261 \\
$\mathrm{Fe}-0 \cdot 35 \mathrm{P}$ & $1 \cdot 206$ & 15599 & 8354 & 270 \\
$\mathrm{Fe}-0 \cdot 45 \mathrm{P}$ & $0 \cdot 384$ & 17490 & 10836 & 294 \\
$\mathrm{Fe}-0 \cdot 65 \mathrm{P}$ & $0 \cdot 353$ & 16666 & 8229 & 288 \\
$\mathrm{Fe}-0 \cdot 80 \mathrm{P}$ & $0 \cdot 375$ & 14145 & 6402 & 241 \\
\hline
\end{tabular}

2006). Forged component shows higher hardness when compared to corresponding rolled and annealed component. This may be because of annealing and accompanying softening of the material.

In the present investigation toroid samples were tested and hysteresis curves (figure 6) were plotted by using hysteresis loop tracer (model: HLT-SOFT) at $50 \mathrm{~Hz}$. The maximum applied field was about 60 Oe. The results obtained are given in table 3 .

The saturation magnetization obtained is in the range of 14,145-17,490 gauss with the maximum value attained for $0.45 \% \mathrm{P}$. The obtained coercivity values varied from $0.35 \mathrm{Oe}$ to 1.24 Oe with a minimum recorded for $0.65 \% \mathrm{P}$. Wire samples yielded similar magnetic response as for toroid samples.
The values obtained in the present investigation indicate that the saturation magnetization at a given magnetizing force increases with phosphorous content up to $0.45 \mathrm{wt} \%$. The higher induction of the phosphorous containing materials can be attributed to their somewhat higher density (Lindskog et al 1977). The saturation magnetization reported for Fe-P alloys by Lindskog et al (1977) varied from 14,700 gauss to 15,200 gauss with maximum at $0.6 \% \mathrm{P}$. In the present investigation the saturation magnetization obtained varied from 14,145 gauss to 17,490 gauss with a maximum at $0.45 \%$ P. Moreover, the saturation magnetization of 14,300 gauss was also reported by Moyer (1998) for $0.45 \% \mathrm{P}$ of $\mathrm{Fe}-\mathrm{P}$ alloy. The improved magnetic properties observed in the present work is attributed to the hot-forging route used for processing the alloys. 
The coercivity of $0.35-1.24$ Oe obtained in this investigation with a minimum recorded for $0.65 \% \mathrm{P}$ is significantly lower than that achieved from pressed and sintered products. For example, Lindskog et al (1977) reported that the coercivity varies from 1.22 Oe to 1.42 Oe with a minimum at $0.70 \%$ P. The lower coercivity may be related to higher density (and hence lower porosity) and relatively low level of inclusions in the alloys investigated. The coercivity level reported (Moyer 1998) for Fe-6.5Si alloy is $0 \cdot 3$ Oe and this may be compared with the coercivity of 0.35 Oe obtained for $\mathrm{Fe}-0.65 \mathrm{P}$ alloy in the present work. Thus, phosphorous is a more effective alloying addition than silicon for lowering coercivity.

Finally, it must be emphasized that the alloys studied exhibited excellent workability despite their high phosphorous content. Thus, sheets/wires can be easily fabricated. This may be significant as soft magnetic materials are required in sheet form for many industrial applications.

\section{Conclusions}

(I) Present investigation based on hot powder-forging route offers a good scope for enhancing density of parts made from $\mathrm{Fe}-\mathrm{P}$ alloys. The density levels obtained are higher than that reported for products made by compacting and sintering route.

(II) It was observed that density increases with phosphorous addition.

(III) It was also observed that hardness of forged and homogenized as well as rolled and annealed parts increases with increase in phosphorous content in the alloy.

(IV) Saturation magnetization was obtained from 14,145 gauss to 17,490 gauss with a maximum for $0.45 \%$ P. Coercivity levels obtained in the present investigation range from 0.35 Oe to 1.24 Oe.

(V) Magnetic properties obtained are better than those reported for comparable $\mathrm{P} / \mathrm{M}$ alloys processed through conventional pressing and sintering route.
(VI) Lowering of coercivity level due to phosphorous addition of $0.65 \%$ is found to be comparable to that resulting from silicon addition of $6.5 \%$, indicating that phosphorous is a more effective alloying addition than silicon for lowering coercivity.

(VII) Alloys exhibited excellent workability despite their high phosphorous content.

\section{Acknowledgement}

The work was supported by DRDO, New Delhi.

\section{References}

Chandra K 2004 Design and development of $\mathrm{Fe}-\mathrm{P}$ based powder metallurgical magnetic materials, $\mathrm{PhD}$ Thesis, IIT Roorkee

Das J 2006 To develop and characterize high density $\mathrm{Fe}-\mathrm{P}$ based $P / M$ alloys, MTech Dissertation, IIT Roorkee

Das J, Chandra K, Mishra P S and Sarma B 2008 J. Magn. Magn. Mater. 320906

Hanejko F G, Rutz H G and Oliver C G 1992 Effects of processing and materials on soft magnetic performance of powder metallurgy parts, Presented at the 1992 Powder Metallurgy World Congress, San Francisco, CA (www.hoeganaes.com)

Hopkins H E and Tipler H R 1958 J. Iron Steel Institute 188218

Lund 1985 Int. J. Powder Metall. Powder Technol. 2147

Lindskog P, Tengzelius J and Kvist S A 1977 Powder Metall. 1097

Moyer K H 1998 ASM Handbook Powder Metall. Appl. 71006

Panasyuk O A and Radomysel I D 1973 Institute of Material Science, Academy of Sciences of the Ukrainian SSR, Translated from Poroshkovaya Metallurgiya 412429

Rutz H G and Hanejko F G 1994 High density processing of high performance ferrous materials, Presented at the international conference and exhibition on powder metallurgy and particulate materials, Toronto, Canada (www.hoeganaes.com) Technical publications library

Shimada Y, Matsunuma K, Nishioka T, Ikegaya A, Itou Y and Koiso T 2003 SEI Technical Review 5646

Sudan A S and Misra P S 1991 Indian Patent No. 184576 